\title{
Forest efficacy trials on phosphite for control of kauri dieback
}

\author{
I.J. Horner, E.G. Hough and M.B. Horner \\ The New Zealand Institute for Plant \& Food Research Limited, Private Bag 1401, Havelock \\ North, New Zealand \\ Corresponding author: ian.horner@plantandfood.co.nz
}

\begin{abstract}
In 2012, trials were established in four kauri forest sites severely affected by kauri dieback (Phytophthora agathidicida $=P$. taxon Agathis, PTA) to determine the potential of phosphorous acid (phosphite) as a control tool. Baseline assessments of 162 trial trees included canopy disease rating, trunk lesion dimensions and lesion activity (recent bleeding/ oozing). Phosphite (Agrifos ${ }^{\circledR} 600$ ) at concentrations of $7.5 \%$ or $20 \%$ was injected $(20 \mathrm{ml})$ at $20-\mathrm{cm}$ intervals around the trunk. Control trees were left untreated. After 1 year, half the previously injected trees were re-injected, in all cases with $7.5 \%$ phosphite. Phytotoxicity symptoms (leaf yellowing, browning or leaf/twig abscission) were noted in some phosphiteinjected trees, particularly where the $20 \%$ concentration was used. After 3 years, many more trunk lesions remained active (expressing ooze, continued expansion) in untreated trees $(58.5 \%)$ than in phosphite-treated trees $(0.8 \%)$. Average lesion expansion after 3 years was $12.7 \mathrm{~cm}$ in untreated and $0.4 \mathrm{~cm}$ in phosphite-treated trees.
\end{abstract}

Keywords Phytophthora agathidicida, PTA, kauri, Agathis australis, control.

\section{INTRODUCTION}

Phytophthora agathidicida (Weir et al. 2015) also known as Phytophthora taxon Agathis (PTA) is a serious problem, killing kauri (Agathis australis) trees of all ages in forests in Northland, Auckland and Coromandel, New Zealand (Beever et al. 2009, 2010; Waipara et al. 2013). The pathogen causes root rot and bleeding cankers at the base of the trunks, resulting in canopy thinning and eventually tree death. Phosphite (phosphorous acid) is a potential tool for treatment of infected and threatened trees. Phosphite has been used extensively for treating phytophthora diseases of many plant species, particularly in horticultural systems, but also in trying to manage various phytophthora diseases in forests and natural ecosystems (Smillie et al. 1989; Hardy et al. 2001;
Garbelotto et al. 2007; Crane \& Shearer 2014). In glasshouse trials Horner \& Hough (2013) demonstrated that phosphite stem injections protected kauri seedlings from $P$. agathidicida attack, and facilitated healing of lesions where infections had already established. This paper reports research on the efficacy of phosphite for controlling kauri dieback in naturally infected forests.

\section{MATERIALS AND METHODS}

Forest trial sites, tree selection and treatment Four trial sites were selected: Huia dam and Whatipu in the Waitakere ranges, Auckland, and Raetea and Omahuta Forest in the Mangamuka ranges, Northland. Both the Auckland sites were 
in naturally regenerating forest, in stands of kauri rickers. Both Northland sites were in plantation kauri, planted by the New Zealand Forest Service in the 1950s to 1970s. All four sites had confirmed diagnoses of $P$. agathidicida in soil or trees.

The trials were established January to March 2012. Only kauri trees showing symptoms consistent with $P$. agathidicida infection (e.g. lesions or bleeding sap at the base of the trunk, and/or thinning or yellowing canopies) were included in the trial. There were 52, 53, 42 and 15 trees in the trials at the Huia, Whatipu, Raetea and Omahuta sites, respectively. Most trees were at the ricker or advanced ricker stage, with girths ranging from 40 to $120 \mathrm{~cm}$.

Before treatments were assigned to trees, all selected trial trees were mapped, measured (girth), and canopy symptoms were scored on a $1-5$ scale (where 1 is healthy and 5 is dead). Most of the selected trial trees had canopy scores of 3 or 4 , indicating moderately to severely thinned canopies. Canopy photographs were taken for future reference, and the trunk base was photographed at cardinal points. Basal trunk lesions (if present) were measured, noting position, maximum height and width. In many cases lesion margins were marked using a chinagraph pencil for future reference. Lesion activity (i.e. whether they appeared fresh and active, or dried and inactive) was noted. Once sufficient trial trees were identified, they were assigned into groups at each site, based on similarity of symptoms. Trees within each group of 'similar' trees were then randomly assigned treatments, such that there was an even number of trees from each treatment in each disease severity group. This ensured that across each site, the 'average' disease severity of trees in each treatment at the start of the trial was similar.

Trees were injected with either a high (20\% ai, Waitakere sites only) or low (7.5\% ai, all sites) phosphite concentration (Agrifos600 ${ }^{\circledR}$ ) using spring-loaded Chemjet ${ }^{\circledR}$ tree injectors. Some trees were left untreated as controls. In January 2013, 10 to 12 months after the initial treatment, half the previously treated trees at each site were re-injected with a low $(7.5 \%)$ concentration of phosphite, regardless of whether they had been treated with the high or low rate at the start of the trial. Remaining injected trees and untreated controls were left untreated, making a total of five different treatments in the trial as follows: (1) 'High PA/low PA': 20\% phosphite (January 2012) and 7.5\% phosphite (January 2013); (2) 'High PA/nil PA': 20\% phosphite (January 2012); (3) 'Low PA/low PA': 7.5\% phosphite (March 2012) and $7.5 \%$ phosphite (January 2013); (4) 'Low PA/ nil PA': 7.5\% phosphite (March 2012); and (5) Untreated control.

All phosphite treatments were applied as a dose of $20 \mathrm{ml}$ every $20-\mathrm{cm}$ around the trunk circumference, injected into the trunk 0.4 to $0.8 \mathrm{~m}$ above the ground. Following removal of the injector, the drilled hole was plugged with silicon sealant. All five treatments were applied at Huia and Whatipu. Only treatments 3, 4 and 5 were applied at Omahuta and Raetea. There have been no further applications of phosphite since January 2013.

\section{Assessments}

In January and June 2013, January and June 2014, and February 2015, tree canopy health and vigour were compared with those in the photographs taken at the start of the trial. The scoring system, based on the original photographs and comparing canopy health and density was: $-2=$ substantially worse, $-1=$ slightly worse, $0=$ similar, $1=$ slightly better, 2 = substantially better. The subjective ratings of 'substantially' or 'slightly' different were based on whether the difference was immediately obvious (substantial) or whether the original photograph and current canopy had to be examined carefully, making comparisons down to the individual twig or leaf level (slight). Canopy photograph comparison data were analysed using a Kruskal-Wallis nonparametric ANOVA. Binoculars were used to check for new shoot growth. At each assessment time, the dimensions of lesions at the base of the trunk were re-measured. Where margins on particular lesions had been marked, any advance of the lesion margin was measured. Where bark at the lesion margin had peeled back and 
healed beneath, often giving a negative distance for lesion advance, this distance was measured and recorded but a zero value was entered for analysis. Lesion advance data were analysed by one-factor analysis of variance on the average per tree, using log-transformed data. Lesion activity, as indicated by freshly oozing sap, was recorded as either not active (healed/dry), active (fresh ooze or sap) or unclear (possibly active).

\section{RESULTS}

\section{Phytotoxicity symptoms}

In canopy assessments made within 6 months to 2 years of initial treatment, phytotoxicity symptoms of leaf yellowing, leaf loss and even some premature branchlet abscission were noted in some phosphite-treated trees, particularly where the high phosphite rate was applied. Between 18 months and 3 years after initial treatment, at the Huia and Whatipu sites, a small number of treated trees died, mostly where the high phosphite rate had been applied (Table 1). In all cases, these trees had shown severe kauri dieback symptoms prior to treatment (data not shown). Where trees survived, the phytotoxicity symptoms were no longer obvious in most trees 2-3 years after treatment, and canopies generally appeared green, although in some cases slightly thinner than at the start of the trial. There were no deaths of phosphite-treated trees in the first 3 years of trials at Raetea and Omahuta, although four out of fourteen untreated trees had died at Raetea, all following rapid basal trunk Phytophthora-lesion expansion causing girdling of the trees.

In a small number of injected trees at the Huia and Whatipu sites, vertical cracks in the bark were noted. These appeared to be related to the injection points, and may be a further symptom of phytotoxicity. This symptom was first noticed in June 2014, and was systematically recorded in February 2015 assessments (Table 1). At the Huia

Table 1 Tree deaths, canopy phytotoxicity symptoms, trees with bark cracks in line with injection points, lesion activity (\%) and mean lesion advance $(\mathrm{mm})$ recorded in Phytophthora agathidicida-infected kauri trees injected with high $(20 \%)$ or low $(7.5 \%)$ rates of phosphite or left untreated in JanuaryMarch 2012 and January 2013. Data are from assessments made 3 years after initial treatment. Letters indicate significance groupings $(\mathrm{P}<0.05)$.

\begin{tabular}{llcccccc}
\hline Site & Treatment & $\begin{array}{c}\text { No. } \\
\text { trees }\end{array}$ & $\begin{array}{c}\text { No. } \\
\text { dead }\end{array}$ & $\begin{array}{c}\text { Phytotoxicity } \\
\text { symptoms }\end{array}$ & $\begin{array}{c}\text { No. with bark } \\
\text { cracks }\end{array}$ & $\begin{array}{c}\text { Lesions } \\
\text { active }\end{array}$ & $\begin{array}{c}\text { Lesion } \\
\text { advance }\end{array}$ \\
\hline Huia & High/low & 11 & 2 & 2 & 4 & $0 \mathrm{a}$ & $5.8 \mathrm{a}$ \\
& High/nil & 10 & 2 & 2 & 4 & $0 \mathrm{a}$ & $1.3 \mathrm{a}$ \\
& Low/low & 10 & 0 & 4 & 4 & $0 \mathrm{a}$ & 0 a \\
& Low/nil & 10 & 1 & 2 & 4 & $0 \mathrm{a}$ & $1.7 \mathrm{a}$ \\
& Control & 11 & 0 & 0 & 0 & $50 \mathrm{~b}$ & $100.6 \mathrm{~b}$ \\
\hline \multirow{6}{*}{ Whatipu } & High/low & 11 & 4 & 0 & 2 & $0 \mathrm{a}$ & $2.5 \mathrm{a}$ \\
& High/nil & 11 & 2 & 2 & 2 & $0 \mathrm{a}$ & $0 \mathrm{a}$ \\
& Low/low & 10 & 2 & 4 & 1 & $0 \mathrm{a}$ & $2.5 \mathrm{a}$ \\
& Low/nil & 10 & 0 & 0 & 2 & $0 \mathrm{a}$ & $0 \mathrm{a}$ \\
& Control & 11 & 0 & 0 & 0 & $43 \mathrm{~b}$ & $30.0 \mathrm{~b}$ \\
\hline \multirow{6}{*}{ Raetea } & Low/low & 14 & 0 & 0 & 0 & $0 \mathrm{a}$ & $5.3 \mathrm{a}$ \\
& Low/nil & 14 & 0 & 0 & 0 & $0 \mathrm{a}$ & $10.0 \mathrm{a}$ \\
& Control & 14 & 4 & 0 & 0 & $69 \mathrm{~b}$ & $194.0 \mathrm{~b}$ \\
\hline Omahuta & Low/low & 5 & 0 & 0 & 0 & $11 \mathrm{ab}$ & $3.8 \mathrm{a}$ \\
& Low/nil & 5 & 0 & 0 & 0 & $0 \mathrm{a}$ & $3.3 \mathrm{a}$ \\
& Control & 5 & 0 & 0 & 0 & $43 \mathrm{~b}$ & $31.9 \mathrm{a}$ \\
\hline
\end{tabular}


and Whatipu sites respectively, vertical cracking was observed in 39 and $17 \%$ of injected trees. No such cracking has been observed in any trees at Raetea and Omahuta.

\section{Canopy health}

After 3 years, changes in the tree canopies were becoming apparent. However, trends in canopy data varied at the four sites, perhaps in response to different factors (Figure 1). At Huia, on average there was a slight decline (though not statistically significant, $\mathrm{P}=0.188$ ) in canopy density in all treatments, reflecting phytotoxicity in injected trees, plus some tree deaths. There was a similar trend at Whatipu $(\mathrm{P}=0.002)$, with the most substantial decline occurring in trees treated with either the high concentration of phosphite, or receiving two applications of the low concentration.

At Omahuta, canopy density had changed little in the untreated trees, but had improved slightly in trees injected once or twice with the low phosphite concentration $(\mathrm{P}=0.172)$, also reflected in new leaf growth in many trees (data not shown). At Raetea, injected trees were, on average, of similar canopy density to that prior to treatment. However, average canopy density/ health of untreated control trees had declined significantly $(\mathrm{P}<0.001)$.

\section{Lesion activity}

Lesion activity 3 years after initial treatment, as indicated by freshly oozing sap at lesion margins, is summarised in Table 1. Very few lesions on phosphite-treated trees were rated as 'active' in February 2014, compared with many active lesions in untreated control trees. On three sites (Huia, Whatipu and Raetea), none of the lesions in phosphite-treated trees showed any signs of recent activity, and at Omahuta a single lesion on one phosphite-injected tree was active in February 2015. In contrast, on the same sites $43-69 \%$ of lesions in untreated control trees were active.

\section{Lesion expansion}

At all four sites, lesion expansion has been greatest in untreated control trees, where many lesions have remained active and advancing (Table 1, Figure 2). In comparison, in trees injected with phosphite very few lesions remained active, lesion expansion since the start of the trial had been negligible, and there were signs of cracking and healing around the margins of almost all lesions. In many cases, lesion expansion in treated trees was recorded as 'negative', as the outer diseased bark initially marked had sloughed off, with healthy bark beneath. In all such cases, the 'negative' lesion advances were assigned a 'zero' value for analyses of lesion expansion data. Cracking and healing of lesions was also noted occasionally on some untreated trees, but this was often overtaken by further waves of PTA advance, something rarely seen in phosphite-treated trees.

There were no obvious or consistent differences in lesion activity and expansion between the various phosphite regimes. All the test treatments have to date been effective at stopping Phytophthora lesion advance.

\section{DISCUSSION}

Evidence from forest trials on 'ricker'-sized kauri trees suggests that trunk injection with phosphite is suppressing the activity of $P$. agathidicida within infected trees. This is consistent with observations on phosphite-treated kauri in glasshouse trials (Horner \& Hough 2013) and on a range of tree species in natural forest systems (Garbelotto et al. 2007; Crane \& Shearer 2014). The best evidence to date in kauri is the differential activity and spread of lesions in phosphite-treated versus untreated trees. Almost all lesions on phosphite treated trees at all four trial sites have stopped expanding and appear to have healed. Whether the treatment is sufficient to save trees already infected and ultimately restore them to full health will become more apparent in assessments over the next few years. The longevity of treatment efficacy and the required frequency of treatment for long-term control are also yet to be determined. There is no evidence to date that two treatments in consecutive years is any more effective than a single treatment, or that the $20 \%$ rate of phosphite is any more effective than 
Figure 1 Comparisons of kauri tree canopy health and density in February 2015 with photographs taken before the first treatment application in January 2012. Data are means for each treatment at each of four forest sites. The scoring system, based on the original photographs and comparing current canopy density was: $-2=$ substantially worse, $-1=$ slightly worse, $0=$ similar, $1=$ slightly better, 2 = substantially better. Trees were treated either once or twice with high $(20 \%)$ or low $(7.5 \%)$ concentrations of phosphite (Phos) or left untreated.

Figure 2 Mean lesion advance in Phytophthora agathidicida-infected kauri trees treated with high $(20 \%)$ or low $(7.5 \%)$ rates of phosphite (Phos) or left untreated. The high phosphite treatments were not applied at the Omahuta and Raetea sites. Treatments were applied in JanuaryMarch 2012 and January 2013 and assessments were made 3 years after initial treatment.

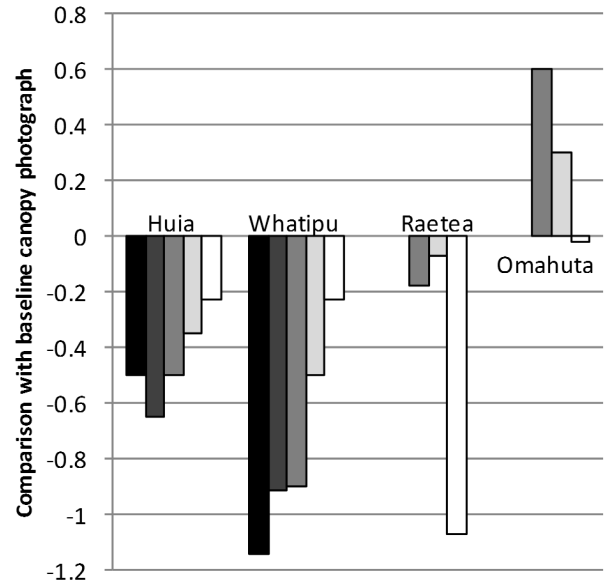

- High Phos/low Phos

口High Phos / nil Phos

口Low Phos/low Phos

口Low Phos/nil Phos

口Untreated

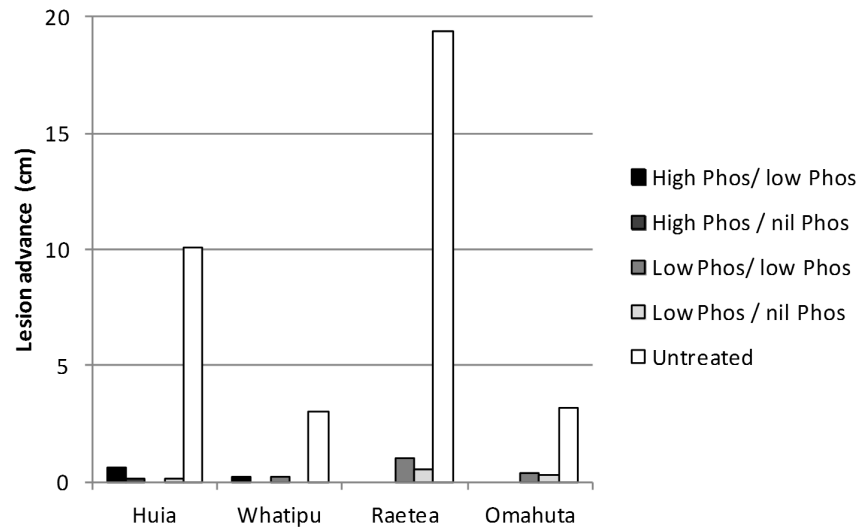

the $7.5 \%$ rate. Given the potential phytotoxicity, especially at higher rates, the sensible option would be to use the lower rate.

The potential phytotoxicity of phosphite remains a concern, and this will have to be monitored carefully in future trials so that rates can be optimised. While healthy trees seem capable of recovering from the toxic effects of high doses of phosphite, there is evidence that severely diseased trees are less tolerant and that phosphite injection may accelerate their decline. The symptom of bark cracking above injection points in some treated trees, possibly an expression of phytotoxicity, has only recently been noted in a small number of trees and will need to be carefully monitored in the future.
However, phosphite treatment of diseased trees in most cases reduced the advance of $P$. agathidicida lesions and has the potential to either protect trees from $P$. agathidicida or restore them to health. Therefore the risk of phytotoxicity causing enhanced decline of severely diseased trees must be balanced against the improvement in health of the majority of trees treated with phosphite. The alternative is, almost inevitably, the death of most kauri trees in P. agathidicida-infected stands if no treatment is made.

The current trials will be monitored for a further 2-3 years to determine longer-term effects, and further trials will be carried out to determine safety thresholds for phosphite treatment of kauri. 


\section{ACKNOWLEDGEMENTS}

This work was funded by the Ministry for Primary Industries on behalf of the Kauri Dieback Joint Agency Response. Manawhenua Iwi, Auckland Council and the Department of Conservation are acknowledged for their assistance with site selection. Thanks also to Duncan Hedderley for assistance with statistical analyses.

\section{REFERENCES}

Beever RE, Waipara NW, Ramsfield TD, Dick MA, Horner IJ 2009. Kauri (Agathis australis) under threat from Phytophthora? In: Phytophthoras in Forests and Natural Ecosystems. Proceedings of the Fourth Meeting of IUFRO Working Party S07.02.09. General Technical report PSWGTR-221, USDA Forest Service, Albany, CA, USA. Pp. 74-85.

Beever RE, Tsai S, Waipara NW, Dick MA, Ramsfield TD 2010. Pathogenicity of Phytophthora taxon Agathis (PTA). Fifth Meeting of the International Union of Forest Research Organisations (IUFRO) Working Party 7.02.09, Phytophthoras in Forests and Natural Ecosystems; March 2010. Rotorua, New Zealand. p. 2 (Abstract only).

Crane CE, Shearer BL 2014. Comparison of phosphite application methods for control of Phytophthora cinnamomi in threatened communities. Australasian Plant Pathology 43:143-149.
Garbelotto M, Schmidt DJ, Harnik TY 2007. Phosphite injections and bark application of phosphite + Pentrabark ${ }^{\mathrm{TM}}$ : control sudden oak death in coast live oak. Arboriculture \& Urban Forestry 33 (5): 309-317.

Hardy G, Barrett S, Shearer BL 2001. The future of phosphite as a fungicide to control the soilborne pathogen Phytophthora cinnamomi in natural ecosystems. Australasian Plant Pathology 30: 133-139.

Horner IJ, Hough EG 2013. Phosphorous acid for controlling Phytophthora taxon Agathis in kauri: glasshouse trials. New Zealand Plant Protection 66: 235-241.

Smillie RH, Grant BR, Guest D 1989. The mode of action of phosphite: evidence for both direct and indirect modes of action on three Phytophthora spp. in plants. Phytopathology 79: 921-926.

Waipara NW, Hill S, Hill LMW, Hough EG, Horner IJ 2013. Surveillance methods to determine tree health, distribution of kauri dieback disease and associated pathogens. New Zealand Plant Protection 66: 235-241.

Weir BS, Paderes EP, Anand N, Uchida JY, Pennycook SR, Bellgard SE, Beever RE 2015. A taxonomic revision of Phytophthora Clade 5 including two new species, Phytophthora agathidicida and P. cocois. Phytotaxa 205 (1): 021-038. 